\title{
LA GESTIÓN DEL MINISTRO IVANISSEVICH Y LA DERECHA PERONISTA: LOS 100 DÍAS DE OTTALAGANO
}

\author{
The Administration of the Minister Ivanissevich and the Peronist Right Wing: \\ The 100 Days of Ottalagano
}

\begin{abstract}
Resumen
Juan Luis Besoky*

Luego de la muerte de Perón y en un proceso de aumento continuo de la represión, tanto estatal como paraestatal, se produjo en agosto de 1974 el reemplazo del ministro de Educación Jorge Alberto Taiana por Oscar Ivanissevich, quien permaneció en el cargo hasta agosto de 1975. A pocos días de asumir, el nuevo ministro designó como rector interventor en la Universidad de Buenos Aires a Alberto Ottalagano. En este artículo me centro en las principales medidas tomadas por el nuevo rector durante su breve gestión y en las principales acciones realizadas por las organizaciones del peronismo de derecha en la Universidad Nacional de Buenos Aires. Entre estas podemos ubicar a la Alianza Libertadora Nacionalista, la Concentración Nacional Universitaria, la Legión Revolucionaria Peronista y el Movimiento Universitario Nacional. Varias de ellas provenían de sectores nacionalistas que, en el marco del proceso de radicalización política de los años sesenta, se habían acercado al peronismo. Otras, en cambio, provenían del peronismo y habían incorporado muchos elementos del nacionalismo de derecha. Todas compartían una cultura política que bajo la idea de la defensa del gobierno de Perón buscaban combatir al comunismo tanto fuera como dentro del Movimiento peronista. La gestión de Ivanissevich y Ottalagano, significó la consolidación de la ofensiva contra la izquierda universitaria.
\end{abstract}

$$
<\text { Peronismo }><\text { Derecha }><\text { Nacionalismo }><\text { Represión }>
$$

\begin{abstract}
After Perón's death, in August 1974, the replacement of the Secretary of Education, Jorge Alberto Taiana by Oscar Ivanissevich (who remained in office until August, 1975) took place. Such replacement occurred in a context of continuous repression exerted by the state and parastatal organizations. A few days after assuming, the new Secretary of Education appointed Alberto Ottalagano as Rector Interventor, at the University of Buenos Aires. In this article, I focus on the measures taken by the new rector during his brief management, and the main actions carried out by right wing Peronist organizations at the University of Buenos Aires. Among such organizations we can mention the Nationalist Liberation Alliance, the National University Concentration, the Peronist Revolutionary Legion, and the National University Movement. Several of them came from nationalist sectors which had approached Peronism within the framework of the political radicalization process of the 1960s. Others came from the Peronism, however, had incorporated many elements of right-wing nationalism. All of them shared a political culture which sought to combat communism both outside and within the Peronist Movement, as a result of the idea of the defense of Peron's government. The management of Ivanissevich and Ottalagano resulted in the consolidation of the offensive against the university left.
\end{abstract}

$$
<\text { Peronism }><\text { Right wing }><\text { Nationalism }><\text { Repression }>
$$

Recibido: 26/05/2017 // Aceptado: 14/07/2017

\footnotetext{
* Becario posdoctoral del CONICET en el Instituto de Investigaciones en Humanidades y Ciencias Sociales (IdIHCS) en la Facultad de Humanidades y Ciencias de la Educación de la Universidad Nacional de La Plata. Profesor en la materia Historia Social Contemporánea, Universidad Nacional de La Plata y de Historia Social General en la Facultad de Bellas Artes. juanelebe@gmail.com
} 


\section{Los inicios de la "depuración" bajo la presidencia Perón}

El domingo 23 de septiembre de 1973 se celebraron las elecciones presidenciales que consagraron ganadora a la fórmula Juan Domingo Perón - María Estela Martínez de Perón con el $61,85 \%$ de los votos. Dos días después de los comicios era asesinado José Ignacio Rucci, dirigente de la CGT, por un comando de Montoneros ${ }^{1}$. La acción, que no fue reconocida de manera pública por la organización, intentaba demostrar a Perón el peso de la organización y era a la vez una advertencia al general Perón en el vano intento de forzarlo a negociar con ellos. Montoneros buscaba con ese hecho político frenar el distanciamiento de la Tendencia Revolucionaria del peronismo y el aval de Perón a los cuadros más ortodoxos del Movimiento. A la postre la ejecución de Rucci tuvo el efecto contrario. Perón reforzó la ofensiva contra los sectores radicalizados del Movimiento y llamó de manera abierta a combatir a los infiltrados. El diario La Opinión del viernes 28 de setiembre consignaba una convocatoria hecha por el Poder Ejecutivo a los gobernadores y vicegobernadores y señalaba dos posturas en el gobierno acerca de cómo se debía "conjurar el brote de violencia":

De acuerdo con lo que trascendió, existirían dos criterios: uno, del ministro Llambí, quien sostiene que debe requerirse; a efectos de la prevención de atentados, secuestros, etc., únicamente el concurso de organismos de seguridad (policía, Gendarmería; en ningún caso las Fuerzas Armadas), y otro que propone la participación de mecanismos de seguridad que se han ido forjando en el propio seno del Movimiento justicialista.

Entre estos últimos aparecen mencionados con un posible papel represivo o "preventivo" las llamadas "fuerzas de seguridad" del propio Movimiento Nacional Justicialista. Entre las que menciona el diario figuran: el Comando de Orientación Revolucionaria (COR) del Gral. Miguel Ángel Iñiguez, el Comando de Organización de Brito Lima, la Alianza Libertadora Nacionalista (ALN) y la Concentración Nacional Universitaria (CNU). Nada dice sobre la Juventud Peronista de la República Argentina (JPRA), organización que recién estaba en conformación, y que luego del asesinato de Rucci cobrará especial impulso. En este sentido lo que menciona el artículo no deja de ser interesante en tanto, como han demostrado las investigaciones posteriores de (Bonavena, 2009), (Franco, 2012) y (Merele, 2015), la solución política que tomó el gobierno fue una combinación de ambos criterios. Es decir, la represión legal a través de las fuerzas de seguridad se conjugó con la represión ilegal mediante organizaciones parapoliciales, como la Triple A conformada por el mismo Subjefe de la Policía Federal Alberto Villar y la custodia del Ministerio de Bienestar Social a cargo de López Rega. Dentro de este esquema represivo cobrarían especial importancia varias de las organizaciones mencionadas anteriormente. De esta forma el sostenimiento e impulso a los sectores derechistas del peronismo incluyó la no condena a la mayoría de las acciones violentas realizadas por estas mismas organizaciones.

\footnotetext{
1 Sobre la autoría, nunca asumida por Montoneros, de la muerte de Rucci véase (Reato, 2011 [2009]).
} 
Un ejemplo sintomático de las organizaciones ortodoxas y de la derecha peronista fue la solicitada que emitió en septiembre, días después de la muerte de Rucci, la Rama Juvenil del Consejo Superior Peronista en la que denuncia la "sinarquía internacional" y a la "oligarquía agazapada" que actúa en conjunto con la izquierda. Además de los cuatro representantes de la rama juvenil firmaban el comunicado los siguientes dirigentes: Ramiro Podetti (Brigadas), Guillermo Piuma (M.A.P.), Carlos A. Moreno Crespo (Comando Evita), Jorge Caterbetti (Juventud Sindical Peronista), H. Amante (Agrupación Peronista 20 de Noviembre), Simón Schumovich (Encuadramiento Juventud Peronista), Oscar A. Vallejos (Agrup. Peronista Nueva Argentina), Juan Carlos Ortiz (Mesa Nacional FREJULI), Pablo Tonelli (Juventud Secundaria Peronista), Jorge Luchetti (FEN-OUP), Juan Carlos Molina (Movimiento de Bases de la Verticalidad Justicialista), Jorge A. Rampoldi (Centro Universitario Peronista), Alvaro Peralta Tanco (Legión Revolucionaria Peronista), Norberto Crinelli (CNU-CJP), Luis Palma (Juventud Peronista Capital), Jorge G. Brocoglia (M. J. P.), José Miguel Tarquín (Agrupación 17 de Octubre), A. Peyloubet (Juventud Peronista de la R. A, Comando Organización) y Juan Carlos De Piña (Juventud Peronista Zona Sur). ${ }^{2}$

Esta solicitada que nucleaba a los llamados "sectores ortodoxos del peronismo" abarcaba desde organizaciones que podemos ubicar en el centro del movimiento como el FEN-OUP hasta otras de la extrema derecha como la CNU. Todas coincidían con su oposición a los sectores de izquierda del peronismo a los que ubicaban dentro de la llamada Tendencia Revolucionaria ${ }^{3}$. La carta de presentación de esta nueva etapa represiva fue el documento, de carácter reservado, que presentó el presidente electo a los gobernadores junto con el Consejo Superior y que se filtró a la prensa a través del diario La Opinión el 3 de octubre de 1974. La importancia de este documento radicaba en que hablaba de una guerra abierta contra el marxismo y la infiltración en el Movimiento y marcaba la profundización y aceleración (aunque no el inicio) del proceso de “depuración”. Luego de hacer un cuadro de situación de lo que el asesinato de Rucci significó -“este estado de guerra que se nos impone"- el documento establecía una serie de directivas: tendientes a 1) decretar el estado de alerta y movilización; 2) realizar una campaña de reafirmación doctrinaria esclareciendo las diferencias fundamentales con el marxismo; 3) informar y comunicar a todos los dirigentes la posición del Movimiento con respecto al marxismo y convocarlos a la lucha; 4) exigir a todos los grupos o sectores del peronismo a que se expidieron públicamente en situación de guerra contra el marxismo; 5) consolidar la unidad del Movimiento para lo cual se debería tomar una serie de medidas, entre ellas:

a) Las orientaciones y directivas que emanen del general Perón en el orden partidario o en función de gobierno, serán acatadas, difundidas y sostenidas, sin vacilaciones ni discusiones de ninguna clase, y ello como auténtica expresión de la verticalidad que aceptamos los peronistas.

2 "Solicitada. Consejo Superior de la Juventud Peronista" en La Razón, 28 de setiembre de 1973.

3 Para un análisis detallado de la derecha peronista véase: Juan Luis Besoky, « La derecha peronista en perspectiva », Nuevo Mundo Mundos Nuevos [En ligne], Questions du temps présent, mis en ligne le 24 mai 2013, consulté le 09 juillet 2017. URL : http://nuevomundo.revues.org/65374 ; DOI : 10.4000/nuevomundo.6537 
f) Las cuestiones que se susciten en el orden partidario se plantearán por vía reservada a la autoridad superior del Movimiento que corresponda en cada rama. Ninguna cuestión interna se considerará más importante que la lucha emprendida ahora. (...)

g) Las objeciones a actos de gobierno producidos por los peronistas que ejercen funciones públicas, se harán también por vía reservada, al funcionario peronista de mayor jerarquía que corresponda, con comunicación a la autoridad superior del Movimiento en cada Rama.

h) Debe excluirse de los locales partidarios a todos aquellos que se manifiesten de cualquier modo vinculados al marxismo, a sus posiciones políticas o a sus actos. (...)

i) En las manifestaciones o actos públicos los peronistas impedirán por todos los medios que las fracciones vinculadas al marxismo tomen participación. (Baschetti, 1999: 66-69) ${ }^{4}$

Los otros seis puntos del documento se referían a: 6) la creación en todos los distritos de un servicio de inteligencia enfocado en esta lucha, 7) la prohibición de cualquier tipo de propaganda marxista "máxime cuando se presenten como si fuera peronista, para confundir", 8) el esclarecimiento entre la población de la posición del Movimiento y de los motivos de la lucha, 9) la utilización de todos los medios que se consideren eficientes, a voluntad de los dirigentes de cada distrito, 10) la recomendación a los "compañeros peronistas en los gobiernos nacional o provinciales" de colaborar activamente de esta lucha utilizando todos los medios del estado y prestando la mayor colaboración a los organismos del Movimiento y 11) referente a las sanciones a aplicar:

La defección de esta lucha, la falta de colaboración para la misma, la participación de cualquier clase en actos favorable al enemigo y aun la tolerancia con ellos, así como la falta de ejecución de estas directivas, se considerará falta gravísima, que dará lugar a la expulsión del Movimiento, con todas sus consecuencias (Baschetti, 1999: 66-69).

En la definición de (Franco, 2012: 179) las dos presidencias de Perón y Martínez de Perón constituyeron un: “...entramado de prácticas políticas: algunas legales, otras cuya legalidad sólo procedimental se amparaba en la 'excepcionalidad' de la situación, otras clandestinas y otras de carácter intrapartidario confundidas con políticas de gobierno". Entre las medidas legales figuraban las modificaciones al Código Penal, la creación de un Consejo de Seguridad Nacional, el empleo de la Gendarmería para custodiar las fábricas, la ley de Prescindibilidad y la Ley de Asociaciones Profesionales. Los objetivos finales de estas medidas eran, según advierte (Servetto, 2010: 196), "la

\footnotetext{
4 Publicado originalmente en La Opinión, del 3 de octubre de 1974.
} 
depuración ideológica, la desmovilización política y el disciplinamiento de los actores sociales".

Las medidas de depuración no se restringieron al interior del Movimiento, a través del desplazamiento de gobernadores afines a la Tendencia, sino que se aplicaron también en la administración pública (a través de la Ley de Prescindibilidad) y en las universidades nacionales (a través de las intervenciones).

En el caso de las universidades, a dos días de la muerte de Rucci, el Ministro de Educación Jorge Taiana, siguiendo las órdenes del Consejo Superior Justicialista, solicitó la renuncia a los profesores Rodolfo Ortega Peña y Eduardo Duhalde debido a críticas a ciertos funcionarios aparecidas en la revista Militancia, que estos docentes dirigía (Millán, 2015). Sin embargo, señala (Rodriguez, 2014) estudiantes, docentes, interventores y el mismo rector de la UBA Rodolfo Puiggrós expresaron su repudio por el alejamiento de estos dos profesores, quienes decidieron desconocer la resolución. Esta situación de incertidumbre continuó hasta diciembre de ese año cuando el ministro hizo efectivo el alejamiento aplicándoles la Ley de Prescindibilidad.

A la solicitud de renuncia de los profesores siguió la del mismo rector Puiggrós, por expreso pedido de Taina, efectivizándose el 2 de octubre. Si bien varios sectores de la juventud peronista y de la izquierda se movilizaron en apoyo del renunciante Taiana nombró en su reemplazo al interventor de la Facultad de Odontología, Alberto F. Banfi, quien renunció a los dos días por presión estudiantil. Finalmente, asumió el secretario general Ernesto Villanueva quien dijo que mantendría la línea política de Puiggrós (Millán, 2015).

Ya desde octubre es posible apreciar en los diarios los asesinatos de militantes peronistas como los casos del periodista José Colombo, secretario de la redacción de $E l$ Norte de San Nicolás y el dirigente peronista Constantino Razzetti en Rosario 5 . El mes anterior, el 26 de septiembre de 1973, había sido asesinado Enrique Grynberg, militante de la JP y un impulsor de los Centros Piloto de Investigación Aplicada en la UBA, en lo que parecía ser una respuesta desde el Ministerio de Bienestar Social al asesinato de Rucci por parte de los Montoneros (Larraquy, 2007: 259).

El 26 de octubre de 1973 se produjeron incidentes con armas de fuego en un homenaje al dirigente José Rucci a un mes de su asesinato, realizado por el Centro Universitario Peronista de Estudiantes, la Legión Revolucionaria Peronista, el Comando Evita y la Concentración Nacional Universitaria. El acto había transcurrido en un aula de la Facultad con la presencia de 200 asistentes, los cuales según consigna el diario, se retiraron disparando sus armas, arrojando botellas con gases y entonando estribillos como "Rucci leal, te vamos a vengar". ${ }^{6} \mathrm{El}$ acto había contado con la adhesión de la CGT y del Consejo Superior del Justicialismo y entre los presentes se encontraban Alejandro Giovenco, Juan Carlos Gómez, Jorge Rampoldi (miembro del viejo Sindicato de Derecho), Raúl Padrés, Rodolfo Galloso y José Luis Nuñez. En el medio del desbande

\footnotetext{
5 El Día, 4 de octubre de 1973 y El Día, 15 de octubre de 1973.
}

${ }^{6}$ La Opinión, 27 de octubre de 1973. 
los participantes destruyeron un templete con una cruz que recordaba a los fusilados de Trelew.

Los meses de octubre y noviembre trajeron también la aparición de varias publicaciones alineadas con la derecha peronista: la revista Alianza, vocera de la ALN, en octubre, y en noviembre dos publicaciones más: Primicia Argentina y El Caudillo de la Tercera Posición, esta última presentada como vocera del Consejo Superior. En ambas publicaciones eran frecuentes los ataques, denuncias y amenazas a figuras de la izquierda peronista.

La publicación Alianza, que figuraba como primer número, incluía el año XXX, vinculándola así a la antigua Alianza de la Alianza de la Juventud Nacionalista de 1943. En su segundo número saludaban la aparición de El Caudillo de la Tercera Posición como una publicación amiga. A su vez, una nota de este ejemplar declaraba que Oscar Bidegain y Miguel Ragone de pasado aliancista, y por entonces gobernadores de Buenos Aires y de Salta respectivamente, ya no pertenecían a la ALN. Se los acusaba de haberse vinculado al marxismo y de haber olvidado en sus provincias la Revolución Nacional Justicialista. Justamente los números siguientes de la ALN continuaran denunciado a los gobernadores que consideraba demasiado cercanos a la Tendencia revolucionaria del peronismo. En su tercer número Alianza publicaba dos notas acusando al mismo ministro Taiana de ser el "ministro de la contrarrevolución", ya que estaba "pésimamente rodeado" y era un "peligro. Al mismo tiempo advertían que la Universidad bajo la conducción de "decanos interventores reconocidamente marxistas" seguía bajo el "esquema liberalmarxista del pasado". Para la ALN la universidad era el "último reducto de la "abortada revolución" del Padrino Cámpora y como tal, absurda, vetusta y atrasada".

La revista El Caudillo de la Tercera Posición era un semanario de información general dirigido por Felipe Romeo. Este era un antiguo militante del Comando $1^{\circ}$ de Mayo de Tacuara, dirigido por Alfredo Ossorio, que luego se había vinculado al Movimiento Nueva Argentina. El Caudillo vio la luz el 16 de noviembre de 1973, cinco días antes de que hiciera su aparición pública la Triple A, para representar la voz de la derecha peronista y contrarrestar la línea editorial de El Descamisado, órgano de prensa de Montoneros. La revista El Caudillo se publicó de manera casi regular hasta fines de 1975 y llegó a vender 9400 ejemplares en los kioscos de la Capital Federal. Una de sus características era el casi total anonimato en el staff, ya que la única firma visible era la de Romeo, y en el editorial siempre a doble página, que funcionaba como una bajada de línea de la derecha peronista. Como primer jefe de redacción figuró el periodista José Miguel Tarquini, un viejo militante de Tacuara y dirigente de la Guardia Restauradora Nacionalista. Éste reclutó colegas que escribían en el diario Crónica y la revista Extra y cuyas simpatías por el fascismo y la falange franquista eran notorias. El resto del staff se completó con integrantes de la Concentración Nacional Universitaria, de la Juventud Peronista de la República Argentina y empleados del Ministerio de Bienestar Social (Besoky, 2010).

El mismo día que salió a la calle El Caudillo, el 16 de noviembre, la JPRA organizó a través del Consejo Superior un acto en la cancha del club Ferrocarril 
Oeste para conmemorar el primer aniversario del regreso de Perón a la Argentina (17 de noviembre de 1972) y el aniversario del combate de la Vuelta de obligado (20 de noviembre de 1845). Este acto contó con la presencia de las organizaciones: CdeO, ALN, JSP, CNU, Brigadas de la Juventud, Movimiento Federal, Escuela Superior de Conducción Peronista y Comando Evita. Por su magnitud constituyó el acto más masivo logrado por la derecha peronista y abiertamente identificada como contraria a la Tendencia, y a la izquierda en general como lo atestiguan algunas consignas cantadas por los militantes: "Con las tripas de Santucho/ vamos a hacer un horquita/para colgar a los trotskos/disfrazados de peronistas" y "Vamos a hacer la patria/ que sea libre; / vamos a hacerla/ con todos los calibres".

A principios de noviembre de 1973 había sido intervenida por el Poder Ejecutivo la provincia de Formosa y sus autoridades destituidas. El año 1974 comenzó con la intensificación de los conflictos al interior del peronismo cordobés y con los intentos de modificación del Código Penal por parte del Ejecutivo. El 19 de enero la guerrilla marxista del PRT-ERP atacó un cuartel militar en la ciudad de Azul. La respuesta del gobierno y de la derecha peronista no se hizo esperar. Perón dio un comunicado con su uniforme de militar llamando a "aniquilar cuanto antes este terrorismo criminal" y convocando al Movimiento Justicialista a movilizar sus efectivos. El discurso terminaba diciendo "Ha pasado la hora de gritar Perón, ha llegado la hora de defenderlo". Tal como señala Lapolla, "la ultraderecha fascista aprovechó la provocación de Azul para cambiar el discurso y el accionar, pasando abiertamente al ataque, los hechos se lo permitían al descolocar a los sectores populares que aparecían divididos y culpables ante el accionar guerrillero" (2005: 312).

Así es como El Caudillo habló de salir a enfrentar abiertamente a los infiltrados y a defender a Perón. Gabriel Cigna, secretario general de la JPRA de la Provincia de Buenos Aires, convocó a una conferencia de prensa en la que además de caracterizar a la Tendencia y a sus dirigentes como gorilas provenientes de la clase media intelectualizada del Partido Comunista o de sectores trotskistas, los trató de "traidores" y "enemigos" y señaló el pase a la clandestinidad de su organización.

De todas formas no hizo falta más presión, desmoralizado por el discurso de Perón que planteaba que no era casual que esos hechos ocurrieran en determinadas jurisdicciones, Bidegain renunció dejando la gobernación en manos de su vicegobernador, Victorio Calabró. Al descalabro que significó el hecho de Azul para la izquierda en general se sumó, como señala (Franco, 2012) la aceleración de los tiempos legislativos para reformular el Código penal con un carácter aún más represivo que en los tiempos de Onganía. En disconformidad con esta reforma y luego de una reprimenda de Perón, "él que no esté de acuerdo se va" les dijo, ocho diputados de la Tendencia renunciaron a sus bancas. Posteriormente fueron expulsados del Movimiento por el CSMNJ (Svampa, 2007).

El 31 de enero hubo un intento de Perón de reunir a toda la rama juvenil con miras a fijar las directivas a partir de entonces. El día anterior se había visto precedido por intensas reuniones entre los sectores que respondían a Montoneros, la JPRA y el secretario de Presidencia (Vicente Solano Lima) debido a la resistencia de los primeros a 
compartir espacio con el CdeO y la CNU. En representación de la JPRA estuvieron cuatro dirigentes: Juan Muciacia, Gabriel Dousdebes, Andrés Poggi y Jorge Fariña, quienes a continuación se trasladaron a la residencia presidencial, donde permanecieron poco más de media hora, agregándose al grupo Julio Yessi. Finalmente la reunión se llevó a cabo pero con la ausencia de la Tendencia revolucionaria (que por voluntad propia decidió no asistir temiendo sufrir la misma suerte que los ocho diputados renunciantes). Esta automarginación de la Tendencia era más bien la consecuencia lógica del continuo proceso de "depuración" que veía sufriendo en todos los ámbitos donde tenía cierta influencia.

Una semana después Perón se reunió nuevamente y de manera exclusiva con la juventud peronista ortodoxa y en dos reuniones ( 7 y 14 de febrero) les ordenó purificar el Movimiento para detener la infiltración. Allí señaló la necesidad de que todas las organizaciones se subordinasen al Consejo Superior del Movimiento que establecerá las directivas a seguir.

En la juventud peronista, en estos últimos tiempos, especialmente, se han perfilado algunos deslizamientos cuyo origen conocemos, y que permiten apreciar que se está produciendo en el Movimiento una infiltración que no es precisamente justicialista. (...) En el país no se ha dado nunca el fenómeno de la infiltración política. Es la primera vez que se da en la historia de la República Argentina esto de gente que se infiltra en un partido o Movimiento político con otras finalidades que las que tiene dicho Movimiento.(...) Lo venimos viendo. Tengo todos los documentos y, además, los he estudiado. Bueno, ésos son cualquier cosa menos justicialistas. Entonces, ¿qué hacen en el Justicialismo? Porque si yo fuera comunista, me iría al Partido Comunista y no me quedaría ni en el Partido ni en el Movimiento Justicialista. ${ }^{7}$

Perón señaló además que el problema no residía en la cantidad de gente que convocaba cada sector sino en el sesgo ideológico de cada dirigente:

Antes de organizamos, tenemos que pensar -la masa ya sabemos lo que es- en el horizonte directivo. Quién es quién en ese horizonte. No interesa que represente mucho o represente poco; para mí, un malvado, aunque represente mucho, es mucho peor que uno bueno que represente muy poco. ${ }^{8}$

Era conocida la enorme capacidad de movilización que poseía la Tendencia Revolucionaria en las manifestaciones y concentraciones como por ejemplo en la campaña electoral. Siempre que la derecha peronista o la burocracia sindical intentó

7 "Palabras del General Perón a la Juventud Peronista" Extraído de: http://www.elhistoriador.com.ar/documentos/vuelta_de_peron/peron_habla_a_la_juventud_peronista.php

8 Palabras del General Perón a la Juventud Peronista" Extraído de: http://www.elhistoriador.com.ar/documentos/vuelta_de_peron/peron_habla_a_la_juventud_peronista.php. 
disputarle en ese ámbito, la Tendencia los superó, en un número como mínimo seis veces mayor (Guillespie, 1987:172). Por ejemplo el acto de la Tendencia en Atlanta el 22 de agosto de 1973, convocó a 50.000 personas mientras que un acto equivalente de toda la derecha peronista el 16 de noviembre juntó 13.000. La diferencia se mantiene también al comparar el acto de una de las organizaciones de la derecha: la JSP el 31 de octubre de 1973 movilizó 3.000 partidarios mientras que un acto equivalente de la JTP tres días después juntó a 20.000. Sin embargo, al decir de Guillespie, "la tragedia de la Tendencia fue que ninguna de sus movilizaciones impresionó a Perón” (1987:172).

En una clara muestra del respaldo de Perón a Yessi y de la indiferencia que mostraba hacia la capacidad de movilización el General dijo:

Así es como veo yo el problema político. Prefiero un dirigente honesto que tenga diez detrás de él y no un deshonesto que tenga diez mil, porque ese es el que me va a derrumbar a la larga. Este es el problema, muchachos, sobre el que hay que pensar y sobre el que hay que empezar a trabajar poco a poco. ${ }^{9}$

La Tendencia respondió a estas directivas a través de Dardo Cabo quien en el editorial N³9 de El descamisado del 12 de febrero de 1974 se preguntó desconcertado:

Ayer éramos "los muchachos" y éramos saludados por el Jefe del Movimiento con emoción por nuestra lucha, se honraban nuestros muertos y ahora, por ser como Perón dijo que tenían que ser los peronistas, por advertir que la lucha aún no ha terminado, que no tenemos todo el poder, que hay que trabajar para conseguirlo, que hay que organizarse y no ceder, por eso ahora nos señalan que hay otros partidos "socialistas" donde podemos ir si queremos. ¿Por qué no nos dijeron antes, cuando peleábamos, que nos pasáramos a otro partido? ¿Dónde estaban éstos que nos tirotean y que preparan los atentados para eliminarnos cuando había que pelear contra Lanusse? ${ }^{10}$

\section{La aprobación de la Nueva Ley Universitaria}

Los meses siguientes continuaron con la sucesión de medidas represivas. En marzo se aprobó, tras un acuerdo entre el peronismo y el radicalismo, la Nueva Ley Universitaria conocida como Ley Taiana ${ }^{11}$, la cual al decir de Friedemann (2011)

\footnotetext{
9 Reunión de Perón con la juventud el 7 de febrero de 1974, en la residencia de Olivos. Tomado de "Palabras del General Perón a la Juventud Peronista", p. 57.

${ }^{10}$ Editorial del El descamisado, N³9, 12 de febrero de 1974.

${ }^{11}$ Respecto a la posición favorable de la CNU a esta ley, véase el reportaje a Rodolfo Gayoso, integrante de la mesa nacional de la CNU, en: "Se derrumba la universidad sectaria, elitista y marxista", El Caudillo, $\mathrm{N}^{\mathrm{o}} 10,18$ de enero de 1974, p. 23.
} 
Besoky. La gestión del Ministro Ivanissevich y la Derecha Peronista: los 100 días de Ottalagano

expresaba una configuración de las fuerzas políticas en tensión pero al mismo tiempo exponía las transformaciones que la izquierda del peronismo buscaba establecer.

La aprobación de esta ley generó una nueva división al interior de la Juventud Universitaria Peronista ya que, si bien reconocía la autonomía y dejaba espacio para no tomar exámenes de ingreso, en el artículo 5 establecía que quedaba "prohibido en el ámbito de la universidad el proselitismo político partidario de ideas contrarias al sistema democrático que es propio de nuestra organización nacional", y en el 51 se afirmaba que podrían intervenirse las casas de altos estudios en caso de "subversión contra los poderes de la Nación" (Rodríguez, 2015; Millán, 2016). Se suponía que con esta ley se iniciaba la llamada normalización institucional, que designaría "rectores normalizadores" para luego continuar con el llamado a elecciones y la redacción de un nuevo estatuto pero, como advierte (Buchbinder, 2014), la normalización prácticamente no llegó a regir jaqueada por los conflictos que se suscitaron entre quienes apoyaban y repudiaban las nuevas designaciones y por el inicio de nuevas intervenciones con el reemplazo de Taiana en agosto de 1974.

En este marco continuaba la depuración del movimiento peronista. El 18 fue detenido Firmenich y varios dirigentes de la JP aunque luego liberados. A fines de febrero se había producido el golpe contra la gobernación de Córdoba a cargo del jefe de la policía provincial Antonio Domingo Navarro, el cual contó en su accionar con el apoyo de grupos armados de la derecha peronista (Servetto, 2010: 79-101; Antúnez, 2015: 205-240).

El $1^{\circ}$ de mayo, con el enfrentamiento público entre Perón y las columnas de la JP de la Tendencia, el presidente comprendió la imposibilidad de subordinar a los sectores radicalizados a sus directivas. Ante la imposibilidad de institucionalizar a la Tendencia y subordinarla al Consejo Superior, Perón disolvió el día 25 del mismo mes la rama Juvenil dentro de las otras dos ramas del Movimiento. Al fin y al cabo, tras haber fracasado en el intento de reencauzar a los sectores combativos bajo una conducción "ortodoxa" la existencia de una rama juvenil carecía de sentido. Un mes después y sin que las relaciones con la izquierda se recompusiesen Juan Domingo Perón falleció el 1 de julio y dejó como presidente a su esposa María Estela Martínez de Perón junto a su fiel secretario (y virtual primer ministro) José López Rega.

Luego de la muerte de Perón continuaron las intervenciones a las provincias vinculadas a la Tendencia: el 9 de agosto fue intervenida Mendoza (a pesar de que el gobernador Martínez Baca se encontraba suspendido por el juicio político iniciado el 5 de junio), el 7 de octubre se intervino Santa Cruz desplazando al gobernador Cepernic y el 18 de noviembre la provincia de Salta destituyendo a Ragone. ${ }^{12}$. Para ese entonces la universidad seguía siendo uno de los ámbitos donde la izquierda contaba aún con una presencia decisiva, razón por la cual la depuración continuó por allí. Según señala (Seia, 2016) "La universidad concentraba una gran efervescencia política estudiantil, no

\footnotetext{
12 Para un análisis detallado de los desplazamientos de gobernadores afines a la Tendencia véase: Antúnez, 2015: 187-318; Servetto, 2010: 53-189. Para un análisis del intento de depuración en todas las provincias peronistas véase: Bonavena, 2009: 164-227.
} 
únicamente de sectores peronistas sino también de un abanico de agrupaciones políticas y desde los sectores reaccionarios se consideraba inadmisible que el área educativa hubiera quedado en manos de la "Tendencia"." . La revista El Caudillo advertía que la universidad era "el último reducto que le queda a la tendencia $[\mathrm{y}]$ tiene que ser saneado cueste lo que cuesta. (El Caudillo, 6/9/1974). Tal como refiere (Friedemann, 2016) sobre este punto coincidían las lecturas de la izquierda y de la derecha del peronismo, por cuanto las universidades "fueron el último bastión que pudo conservar la 'tendencia revolucionaria' del peronismo".

\section{La gestión de Ivanissevich y la cuestión universitaria}

"Por otra, parte no creemos que con clausurar universidades se soluciones nada de fondo. Aquí de los que se trata y en esa tarea estamos desde hace pocos días, desde el mismo momento en que asumí la cartera, es de sanear un organismo que se reconoce padece serias anomalías. Visto en términos médicos, la terapia no puede ser nunca matar al paciente... Salvo que el paciente muera de muerte natural o se autoelimine...".

\section{Oscar Ivanissevich ${ }^{13}$}

La "depuración” en las Universidades se profundizó a partir del 14 de agosto de 1974 cuando Jorge Alberto Taiana fue obligado a renunciar al Ministerio de Cultura y Educación que conducía desde mayo de 1973. Ya desde el mes anterior El Caudillo celebraba la purga contra los sectores de la Tendencia y anticipaba:

Después que se logre frenar el ataque externo va a haber que dedicarse a poner en orden la casa. Sin Perón no nos podemos dar el lujo de tolerar la presencia de traidores. Este es un anuncio concreto, otro de los anticipos de EL CAUDILLO: el 'operativo limpieza' en los elencos gubernamentales va a ser más profundo de lo que muchos suponen y puede llegar a involucrar, incluso, a personas que ahora detentan la jerarquía de ministros. ${ }^{14}$

En lugar de Taiana fue nombrado Oscar Ivanissevich ${ }^{15}$ quien en su discurso pronunciado el Día del Maestro el 10 de septiembre de 1974 planteó la necesidad del "cierre de

${ }^{13}$ Declaraciones del ministro a la revista Las Bases, №110, 10 de septiembre de 1974, p. 7.

${ }^{14}$ El Caudillo, $\mathrm{N}^{\circ} 35,19$ de julio de 1974.

${ }^{15}$ De familia croata, Ivanissevich había nacido en Buenos Aires en 1895. Estudió medicina y se formó como cirujano. Fue titular de la Cátedra de Clínica Quirúrgica de la Facultad de Ciencias Médicas de la UBA, renunciando en 1945 por enfrentamientos con las fuerzas reformistas por oponerse a la participación estudiantil en el gobierno de la Universidad En 1946 fue nombrado interventor de la facultad de Ciencias Médicas de la UBA cargo que ocupó hasta su designación como embajador en Estados Unidos entre 1946 y 1948 y jefe de la Representación Diplomática ante la Unión Panamericana en Washington (1947-1948). Luego entre febrero de 1948 y mayo de 1950 fue Ministro de Cultura y Educación durante 
las universidades subvertidas para asearlas, ordenarlas y normalizarlas". Según Abbatista y Carnagui, "A nivel universitario, se inauguró entonces un período de cesantías masivas entre los trabajadores docentes y no docentes, así como de detección y acorralamiento por mecanismos en apariencia sutiles de los estudiantes politizados" (2014: 10).

En el número 39 del 16 de agosto de 1974 El Caudillo celebraba la renuncia de Taiana bajo el título "Ganó El Caudillo" mientras acusaba a la gestión del ex ministro como el "Ministerio de la Infiltración". A continuación otra nota en la misma revista se quejaba del estado general de la Facultad de Filosofía y Letras, la cual "ha sido, y es, tristemente célebre desde hace muchos años, por haberse constituido en un laboratorio especializado para la construcción de ideologías antinacionales y su difusión, como así también para la formación de cerebros y activistas de la subversión". Entre los principales cuestionamientos señalaban que allí se forjaba la ideología de Montoneros, se habían reemplazado materias por cursos marxistas, docentes sin título eran reclutados en las filas de JUP y el nivel de estudios como la situación. administrativa eran deplorables. ${ }^{16}$

Las principales medidas del nuevo ministro implicaban una rectificación del rumbo seguido hasta entonces, entre las cuales destacaba su rechazo a la investigación científica "un gasto que no pueden soportar los países en desarrollo" y el rechazo al ingreso irrestricto. Como bien destaca (Friedemann, 2016):

Su discurso era tradicionalista, nacionalista-católico y anticomunista. Acusaba a "la conjura internacional" del marxismo por la situación que se vivía en "las universidades sublevadas", por "lavarle el cerebro a alumnos y maestros", mientras llamaba a "una lucha a muerte para conservar la Patria de San Martín y Perón". Una biografía familiar lo recordará por "haber logrado que la guerrilla saliese de la Universidad".

Su designación generó un rechazo masivo en la comunidad universitaria que implicó la toma del Rectorado y de varias facultades por parte de estudiantes y docentes. El rector Héctor Laguzzi apoyó públicamente la toma mientras denunciaba que se estaba preparando "una nueva noche de los bastones largos" por las "fuerzas antiperonistas" (Rodríguez, 2015: 51). Entre fines de agosto y principios de septiembre se desarrollaron clases callejeras y movilizaciones estudiantiles que fueron reprimidas, al mismo tiempo que se generalizaban las detenciones y allanamientos en las facultades. Las tomas de los estudiantes contaron con el apoyo de la decana de Filosofía y Letras, Adriana Puiggrós y del decano de Arquitectura, Alfredo Ibarlucía.

Frente a esto la respuesta de la derecha del peronismo no se hizo esperar. A principios de septiembre se produjeron atentados contra la decana Puiggrós y el rector del Colegio Nacional de Buenos Aires, Raúl Aragón. El 7 de septiembre una bomba

el primer gobierno de Juan Domingo Perón. Su primera gestión se destacó por la prolífica creación de nuevas escuelas, el abandono del arancel para la educación secundaria y universitaria y la edición y difusión masiva de la Marcha Peronista (tuvo que ver con la versión final de la letra) y hay quienes sostienen que fue removido por una disputa con Eva Perón, a quien en 1950 operó de apendicitis. Falleció en 1976.

${ }^{16}$ El Caudillo, $\mathrm{N}^{\mathrm{o}} 39,16$ de agosto de 1974, pp. 7-9. 
contra el domicilio de Laguzzi, que posteriormente se adjudicó la Triple A, asesinaba a su hijo pequeño de sólo cinco meses. Un día antes El Caudillo, que actuaba como la voz no oficial de la Triple A, responsabilizaba a "Adriana Puiggrós ("una marxista de triste apellido") y a Laguzzi del "desorden que un grupo de marxistas irresponsables intenta perpetuar en las casas de estudio", y proponía una solución "drástica y definitiva", "cirugía mayor" para terminar con el "nido subversivo", "así haya que cerrar por un tiempo la puerta de unas cuantas facultades" (Friedemann, 2016: 14).

Al analizar la intervención en las universidades El Caudillo continuaba con las analogías indicando que "la izquierda marxista y la derecha liberal mantienen la unión democrática en la educación.” De esta manera se buscaba justificar la intervención ya que no era el peronismo el que estaba en las facultades sino una "trenza liberal-marxista" donde se hallaban "quienes oficiaban de aparato de superficie de la guerrilla". Para la revista, "la solución a la cuestión universitaria debe ser drástica así haya que cerrar por un rato las puertas de algunas facultades. Ahora no existe nada más antinacional que la universidad. El último reducto que le queda a la Tendencia debe ser saneado cueste lo que cueste". A esta campaña se adhería la CNU que en la revista de la Concentración de la Juventud Peronista declaraba:

Concentración Nacional Universitaria, representa, leal y legalmente, la absoluta exaltación doctrinal del peronismo en la universidad que, dejando de ser retórica, adquiere dimensiones más amplias, más profundas, acrecentada en el "saber formativo" como constante prédica. Ello implica la lucha frontal contra el enemigo sinárquico en el campo universitario, absolutamente en sus manos, pues la universidad nacida de la mentalidad nominalista-jesuítica ha permanecido al margen de las realidades del país y su itinerario histórico, ha sido la constante aceptación de las más variadas corrientes de la decadencia y la corrupción Intelectual como el racionalismo, iluminismo, liberalismo, marxismo, trotzkismo, progresismo o judeo-cristianismo, enemigos de la Nación, enemigos del Justicialismo absolutamente nacional, humanista y cristiano cuyo fundamento arranca desde la Tradición cultural de Occidente prolongada en la doctrina y en el pensamiento del General Perón. ${ }^{17}$

En este ambiente convulsionado, en el cual la organización Montoneros había resuelto pasar a la clandestinidad ${ }^{18}$, Ivanissevich dio un discurso por el día del maestro

\footnotetext{
17 "Por qué mueren nuestros compañeros" en Concentración de la Juventud Peronista, Año I, №1, septiembre de 1974, pp. 3.

${ }^{18}$ El pase a la clandestinidad fue informado por la conducción el 6 de septiembre de 1974. Esto dejaba en una situación complicada a sus militantes de superficie, como fue el caso de Miguel Talento, dirigente de la Juventud Universitaria Peronista, quien debió salir a aclarar que su organización continuaba funcionando como siempre (Rodríguez, 2015: 52).
} 
el 10 de septiembre donde planteó que "se han utilizado las escuelas de la República, las aulas, los pizarrones y las tizas que el pueblo paga, para, con el pretexto de la acción gremial, instar a profesores, maestros y alumnos al desorden y a la rebeldía" (...) En su visión existían grupos políticos "que desde los jardines de infantes a la Universidad quiebran el orden constitucional lavando los cerebros a alumnos y maestros para tener maestros, estudiantes y profesionales frustrados que sirvan a sus designios extranjerizantes y subalternizantes". El ministro finalizaba su alocución justificando la inminente intervención de las universidades a través de la ley recientemente aprobada ${ }^{19}$.

Frente a esto Raúl Laguzzi y el secretario general Ernesto Villanueva convocaron, en una conferencia de prensa, a realizar un plebiscito obligatorio la próxima semana con miras a que cada estamento se pronuncie sobre la política universitaria desarrollada. La respuesta de la derecha peronista, nuevamente dada a conocer a través de El Caudillo no se hizo esperar. Bajo el título "¿Qué está pasando en la universidad? Nada, que la van a nacionalizar" un informe especial felicitaba al ministro por su discurso y sostenía:

Nuestra Universidad es un engendro en el cual una minoría de vagos gobierna dictatorialmente a una mayoría que quiere enfocar las cosas seriamente y utilizar las aulas para su fin lógico: estudiar. Pero no, esto no puede ser cuando gobierna la tendencia, es cosa de "reaccionarlos". Por eso el nacional-justicialismo tiene un trabajo pendiente: el de poner definitivamente las cosas en orden. Para eso habrá que empezar de cero y eliminar a muchos francotiradores contra el país. Por eso hace falta energía y mano dura. Esperamos que no se economicen. ${ }^{20}$

En ese mismo número una solicitada a página entera firmada por la Agrupación Peronista de Trabajadores Universitario señalaba, en abierto rechazo al plebiscito:

PORQUE todo ZURDO tiene su puesto esperando en la

Universidad de Buenos Aires.

PORQUE no son Argentinos.

PORQUE para ellos su Patria es MOSCU.

PORQUE cada acto político se realiza bajo la bandera roja, la hoz y el martillo.

PORQUE para nosotros la única bandera es la azul y blanca. SI TODO ESTO ES RECONSTRUCCION

\footnotetext{
19 "Son tales los excesos y arbitrariedades cometidos que en más de un caso cabe la intervención lisa y llana tal como lo establece el Artículo 51 de la Ley Universitaria cuando dice: a) Manifiesto incumplimiento de la Ley. b) Alteración grave del orden público. c) Conflicto insoluble dentro de la Universidad. d) Subversión contra los poderes de la Nación. Más aún: para muchos lo que se impone es el cierre de las universidades subvertidas para asearlas, ordenarlas y normalizarlas." En "Mensaje de su excelencia el señor Ministro de Cultura y Educación Doctor Oscar Ivanissevich, 10 de setiembre de 1974". Buenos Aires: Ministerio de Cultura y Educación. Disponible en: http://www.bnm.me.gov.ar/giga1/documentos/EL000059.pdf

${ }^{20}$ El Caudillo, № 44, 20 de septiembre de 1974, pp. 8-9.
} 
UNIVERSITARIA, júzguelo Ud., como Argentino.

CONSECUENCIA: Seguimos bajo la tutela de la Doctrina

Nacional Justicialista, adheridos a la CGT y los lineamientos

enmarcados por las 62 Organizaciones, únicos herederos de la

Política Gremial que responde hasta las últimas instancias a

las directivas del Gral. PERON y de su legítimo heredero EL

PUEBLO y por ende a la Compañera ISABEL.

7.000.000 de votos han PLEBISCITADO un Gobierno,

le sugerimos a los BOLCHES que se vayan a hacer un

PLEBISCITO a MOSCÚ.

De todas formas el plebiscito no pudo realizarse porque tres días después de la conferencia de prensa, el 17 de septiembre, un decreto firmado por la presidente y el ministro Ivanissevich establecía la intervención de la UBA amparado en el art. 51 de la recientemente aprobada ley universitaria ${ }^{21}$. Como interventor hasta el 31 de diciembre de 1974 figuraba Alberto Ottalagano, reconocido militante del peronismo de derecha.

\section{La intervención de Ottalagano}

Alberto Ottalagano había nacido en Santa Fe en 1924, y se graduó de abogado en la Universidad Nacional del Litoral, donde también se doctoró en filosofía. En su adolescencia concurrió al Colegio Nacional de Santa Fe y allí tuvo como profesores entre otros a José María Rosa y Jordán Bruno Genta (Macor, 1997). Fue jefe de Juventudes de la Unión Nacionalista del Interior (UNIR) en Santa Fe y secretario de la Agrupación Tradicionalista y Centro Martín Fierro de Paraná. También se destacó delegado de la Alianza Libertadora Nacionalista en el norte santafecino. Desde el nacimiento del peronismo, Ottalagano se incorporó a sus filas y fundó el Movimiento de Centros Cívicos Peronistas. En 1946 integró la Junta Renovadora del radicalismo, en Entre Ríos, e intervino en la fundación de la Confederación General Universitaria (CGU). Cuando cayó el gobierno de Juan Domingo Perón, actuó en la resistencia peronista y fue detenido por su participación en el levantamiento de junio de 1956. Ottalagano, durante los años de exilio de Perón, fue miembro del Comando Estratégico y Táctico del peronismo. Muchas veces se declaró públicamente fascista, partidario de la ideología perpetrada por Hitler, a quien reivindicó ubicándolo en su particular escala de valores a la altura de Mussolini, Franco, y, sobre todo, su ídolo de entrecasa, el general legionario español Millán de Astray, permanentemente evocado en sus escritos. Exhortaba al peronismo a convertirse en el acristianamiento más puro del fascismo, al tiempo que juzgaba que esa doctrina constituye la afirmación viril de la catolicidad (Gttlin, 1998). Entre otras obras jurídicas, históricas y filosóficas, publicó: Soy fascista, y qué?: Alberto Ottalagano, una vida al servicio de la Patria (1983), Tres momentos de una idea: nacionalismo, peronismo y justicialismo (1986) y Rosas forjador del Estado argentino (1986).

\footnotetext{
${ }^{21}$ Decreto No865/74. Publicado en el Boletín Oficial el 29 de septiembre de 1974.
} 
Al nombramiento de Ottalagano le siguieron en los meses venideros otros rectores interventores como Pedro Arrighi en la Universidad Nacional de La Plata en octubre de 1974 y Remus Tetu en la Universidad Nacional del Sur en marzo de $1975^{22}$. Estos rectores contaron con la colaboración de sectores de la derecha peronista, predominantemente la $\mathrm{CNU}$, quienes se dedicaron a romper asambleas, tomar facultades y en muchos casos actuar como celadores (armados) en los colegios dependientes de la Universidad. En el caso de la UNLP señalan (Abbatista y Carnagui, 2014:18).

El 8 octubre de 1974, las amenazas que había vitoreado contra algunos de los dirigentes de la UNLP se cumplieron. Dos de los principales pilares del proyecto institucional generado al calor del documento Bases para una nueva Universidad, Rodolfo Achem y Carlos Miguel, fueron secuestrados y asesinados por un grupo en el que participaron militantes de la CNU. Luego de estos hechos, la UNLP fue cerrada e intervenida. Recién volvería a abrir sus puertas al año siguiente con un drástico cambio de orientación en sus políticas. La "Misión Ivanissevich" había triunfado. La CNU dejaba de ser una de las tantas organizaciones de derecha extrema dentro del peronismo para ocupar en adelante un lugar indiscutible dentro del creciente espacio de la represión paraestatal.

En la UBA la gestión de Ottalagano, que duró 3 meses y medio, desde el 17 de septiembre al 26 de diciembre de 1974, tenía como objetivo declarado, según (Seia, 2016):

... "higienizar" los claustros de los "elementos extranjerizantes y comunistas" que habían copado las aulas y que generaban el "caos social". Para ello, había que cerrar las universidades, “asearlas, ordenarlas y normalizarlas", para así hacer cumplir la ley universitaria y lograr el orden necesario para el desarrollo de las tareas académicas.

Una de sus primeras medidas fue imponer un asueto en todos los establecimientos dependientes de la UBA, exceptuando los hospitales, interrumpiendo así todo tipo de actividad institucional hasta mediados de octubre. Otra de sus acciones, según destaca (Friedemann, 2016), fue derogar la mayoría de las resoluciones anteriores, aprobadas durante la gestión de Puiggrós, Villanueva, Solano Lima y Laguzzi. A esto se sumaron las resoluciones mediante la cual dejó cesantes a todos los decanos y funcionarios jerárquicos de las diferentes facultades e instituciones de la universidad, como por

${ }^{22}$ Respecto a las intervenciones en otras universidades nacionales, señalan Califa y Millán: Como se advierte, la "misión Ivanissevich" reconoce distintos cortes temporales, según de que Universidad se trate. La primera casa de estudios asolada por este fenómeno fue la UBA, donde la intervención tuvo mayor intensidad y letalidad durante el último trimestre de 1974. En esos mismos meses recién comenzaban las intervenciones en otras instituciones, que reconocieron los ciclos más violentos durante 1975, inclusive después de la gestión de Ivanissevich (2016: 26). 
ejemplo los decanos de Farmacia (Laguzzi), Filosofía y Letras (Puiggrós), Ciencias Exactas (Dussel) e Ingeniería (Roulet), mientras que el de Derecho (Kastelboim) ya había renunciado días antes. Las resoluciones abarcaban incluso a aquellos docentes nombrados interinamente desde la asunción de Puiggrós ${ }^{23}$. Para la "depuración" y "saneamiento" de los claustros universitarios el rector se valió, como bien destaca (Seia, 2016: 33), de la "Ley de Prescindibilidad que lo habilitaba a dar de baja por razones de seguridad al personal de la administración pública; y por otro, a los artículos 5 y 11 de la Ley Universitaria”. Asimismo nombró nuevas autoridades, muchas de las cuales ya habían sido funcionarios durante la dictadura anterior. Entre los más notables, por su clara ubicación dentro de la derecha peronista, encontramos al jesuita Raúl Sánchez Abalenda en Filosofía y Letras y a Raúl Zardini en Ciencias Exactas.

Entre las reformas institucionales que intentó la gestión de Ottalagano merecen destacarse el traspaso de las carreras consideradas como más conflictivas: Ciencias de la Educación, Psicología y Sociología a la órbita directa del Rectorado. Posteriormente hubo planes para transferir la carrera de Sociología a la facultad de Derecho como una "orientación" de la carrera de Abogacía y crear con Psicología una nueva facultad (Friedemann, 2016: 24).

Todas estas medidas serían acompañadas con la creación de un "cuerpo de celadores" por lo general armados, encargados de vigilar los pasillos e ingresos de las facultades. Según Friedemann, este cuerpo de celadores estaba "a cargo de Jaime Lemos, funcionario del Ministerio de Bienestar Social y hombre confianza de López Rega. Si bien la composición, funciones y modos de acción de ese cuerpo represivo no fueron publicitados por el rectorado, la institución mencionó 800 integrantes, mientras que los medios de prensa afirmaban que se trataba aproximadamente de 2 mil miembros de "reconocida militancia nacionalista". En el caso de Lemos, se trataba de un correntino que había sido militante de la ALN y que durante los años sesenta figuraba como secretario general de la publicación de la derecha peronista Retorno y como redactor de Patria Barbara. Para esta publicación había entrevistado al antiguo dirigente de la ALN Juan Queraltó en enero de 1965 durante su exilio en Paraguay. En 1973 Lemos ocupaba un cargo en la Dirección Política del Ministerio de Bienestar Social, al que había ingresado durante la gestión anterior de Francisco Manrique.

\section{La derecha peronista en la universidad}

Llegados a este punto es conveniente preguntarnos quiénes eran los militantes y agrupaciones que acompañaron la gestión de Ottalagano. Si bien algunos de ellos han sido mencionados anteriormente vale la pena profundizar la cuestión. Ya desde el año 1973 se había ido conformando una coalición de organizaciones juveniles provenientes del nacionalismo de derecha y del peronismo ortodoxo que, a pesar de su poco peso en el alumnado eran bastante activas. Estas organizaciones habían conformado la Coordinadora de Estudiantes Universitarios Peronistas (CEUP) que no

\footnotetext{
${ }^{23}$ Para el listado de las diversas resoluciones y medidas de Ottalagano véase: Friedemann, 2016: 18-24 y
} Seia, 2016: 32-33. 
sólo se enfrentaba a la Tendencia revolucionaria del peronismo sino también al resto de la izquierda universitaria. En la revista El Caudillo de septiembre de 1974 habían sacado una solicitada que con el título "Estudiantes "en serio" daba cuenta de las principales coordenadas ideológicas que los guiaban. Allí sostenían:

Los estudiantes universitarios peronistas decimos presente en la hora de rescatar la Universidad de la conjura internacional sinárquica.

Y AFIRMAMOS UNA UNIVERSIDAD:

Que esté consustanciada con el Pueblo y sólo al servicio de la Nación y de la Patria,

Que se integre libre y armónicamente a la Comunidad Organizada, siendo factor de cohesión en el seno del Estado Nacional, como lo estableciera en la Doctrina Peronista el Tte. Gral. Perón. (...) POR ESO RECHAZAMOS;

La Universidad como último reducto de las ideologías antinacionales y sus consecuencias sociales: subversión, guerrilla, corrupción espiritual y material del hombre argentino.

La Universidad que realiza la destrucción de toda verdadera vida intelectual, la degradación de la Ciencia y el Saber, el reemplazo de la Tradición Cultural Nacional por esquemas bolcheviques, que permite el egreso de masas ignorantes e incapacitadas para cualquier actividad intelectual seria, "ideologizadas" y enfrentadas a un pueblo que jamás entendieron. (...)

Firmando e integrando la CEUP figuraban las siguientes organizaciones: la Concentración Nacional Universitaria(C.N.U.), el Movimiento Universitario Justicialista (M.U.J.), el Movimiento Universitario Nacional (M.U.N.), la Línea Peronista para la Liberación y el Comando Evita - Centro Universitario Peronista (C.U.P.). Sin embargo estas no eran las únicas organizaciones que integraban la coordinadora. Si prestamos atención a un "cuadro sinóptico de situación" elaborado por la revista de la derecha liberal antiperonista Carta Política, la cual elaboraba detallados informes periódicos dirigidos al mundo empresarial y de la dirigencia política, podemos encontrar los siguientes datos: 


\begin{tabular}{|c|c|c|c|c|}
\hline Agrupaciones & Origen & Dirigentes & Situación & Vinculaciones \\
\hline $\begin{array}{c}\text { Alianza } \\
\text { Universitaria } \\
\text { Nacionalista }\end{array}$ & $\begin{array}{l}\text { Nace en 1973, como } \\
\text { versión universitaria de } \\
\text { la Alianza Libertadora } \\
\text { Nacionalista (ALN) } \\
\text { refundada ese año por } \\
\text { Juan Queraltó. }\end{array}$ & $\begin{array}{c}\text { Horacio } \\
\text { Barros }\end{array}$ & $\begin{array}{l}\text { Es una agrupación de } \\
\text { poca envergadura que } \\
\text { actúa exclusivamente } \\
\text { en la Universidad de } \\
\text { Buenos Aires }\end{array}$ & $\begin{array}{l}\text { Integra la Coordinado- } \\
\text { ra de Estudiantes Uni- } \\
\text { versitarios Peronistas } \\
\text { (CEUP) }\end{array}$ \\
\hline $\begin{array}{l}\text { Legión } \\
\text { Revolucionaria } \\
\text { Peronista }\end{array}$ & $\begin{array}{c}\text { Se constituye en 1973, } \\
\text { en base a grupos de } \\
\text { origen nacionalista que } \\
\text { actuaban en la Facultad } \\
\text { de Derecho de Buenos } \\
\text { Aires }\end{array}$ & $\begin{array}{l}\text { Horacio } \\
\text { Calderón }\end{array}$ & $\begin{array}{c}\text { Se ha autodisuelto } \\
\text { hace pocos días, para } \\
\text { facilitar la incorpora- } \\
\text { ción de la juventud a } \\
\text { las distintas ramas del } \\
\text { Movimiento. }\end{array}$ & $\begin{array}{l}\text { Impulsó la consti- } \\
\text { tución de la CEUP. } \\
\text { A principios de este } \\
\text { año la agrupación } \\
\text { fue separada por el } \\
\text { Consejo Superior del } \\
\text { Movimiento }\end{array}$ \\
\hline $\begin{array}{c}\text { Concentración } \\
\text { Nacional } \\
\text { Universitaria }\end{array}$ & $\begin{array}{l}\text { Nace hacia el año } 1964, \\
\text { en la ciudad de La Plata, } \\
\text { bajo la inspiración del } \\
\text { Dr. Disandro, reivindi- } \\
\text { cando la "Ley Guardo". }\end{array}$ & $\begin{array}{l}\text { Patricio } \\
\text { Fernández } \\
\text { Rivero }\end{array}$ & $\begin{array}{l}\text { Tiene estructuras de } \\
\text { importancia en La } \\
\text { Plata, Buenos Aires y } \\
\text { Mar del Plata. Pese a } \\
\text { que la agrupación es } \\
\text { universitaria, actúa en } \\
\text { otros medios }\end{array}$ & $\begin{array}{c}\text { Integra la CEUP. Está } \\
\text { vinculada a sectores } \\
\text { sindicales, especial- } \\
\text { mente a la regional } \\
\text { Mar del Plata de la } \\
\text { CGT. }\end{array}$ \\
\hline
\end{tabular}

\begin{tabular}{|c|c|c|c|c|}
\hline $\begin{array}{c}\text { Movimiento } \\
\text { Universitario } \\
\text { Nacional }\end{array}$ & $\begin{array}{c}\text { Aparece en Córdoba en } \\
\text { el año 1968, siendo en- } \\
\text { tonces la única agrupa- } \\
\text { ción no izquierdista que } \\
\text { actuaba en los claustros } \\
\text { cordobeses }\end{array}$ & $\begin{array}{l}\text { José Luis } \\
\text { Nuñez }\end{array}$ & $\begin{array}{l}\text { Sus cuadros más im- } \\
\text { portantes están en Cór- } \\
\text { doba y Buenos Aires. } \\
\text { tiene gravitación en la } \\
\text { Facultad de Derecho } \\
\text { de Córdoba }\end{array}$ & $\begin{array}{c}\text { Está vinculada a la } \\
\text { CEUP. En Córdoba } \\
\text { se vincula a sectores } \\
\text { liderados por Julio } \\
\text { Antún. }\end{array}$ \\
\hline $\begin{array}{l}\text { Movimiento } \\
\text { Universitario } \\
\text { Justicialista }\end{array}$ & $\begin{array}{l}\text { Se constituyó en } 1974 \\
\text { nucleando a jóvenes } \\
\text { universitarios peronistas } \\
\text { que adhieren a la línea } \\
\text { sustentada por "El Cau- } \\
\text { dillo". }\end{array}$ & $\begin{array}{l}\text { Carlos } \\
\text { Roca }\end{array}$ & $\begin{array}{l}\text { Es una agrupación de } \\
\text { poca envergadura que } \\
\text { actúa exclusivamente } \\
\text { en la Universidad de } \\
\text { Buenos Aires }\end{array}$ & $\begin{array}{l}\text { Integra la CEUP. A } \\
\text { través de la revista "El } \\
\text { Caudillo", se vincula } \\
\text { a distintos grupos del } \\
\text { Peronismo Ortodoxo. }\end{array}$ \\
\hline
\end{tabular}

Cuadro extraído de "El futuro del peronismo" Carta Política, No 14, verano de 1975, pp. 12-14 (selección).

Como hemos visto anteriormente la Alianza Libertadora Nacionalista, de larga tradición en el peronismo desde la década de 1940 (Besoky, 2014) había vuelto a organizarse a partir de 1973 con el regreso de unos de sus dirigentes históricos: Juan Queraltó. Si bien su reaparición congregó antiguos militantes aliancistas había también jóvenes que provenientes del nacionalismo de derecha o desde el peronismo anticomunista se habían sumado. La fecha oficial de su aparición había sido el 21 de mayo de 1973, en una conferencia de prensa efectuada en la sede de la organización, 
Cangallo (actual calle Perón) 1251. Según relatara El Día se encontraban presentes en la conferencia el secretario general de la organización, Jorge Giarini; el secretario gremial, Alberto Kortanje, y Alejandro Recio y Carlos Tocagni, de la Alianza Universitaria Nacionalista y de la Unión Nacionalista de Estudiantes Secundarios, respectivamente. El secretario de prensa de la ALN Horacio Calderón, había leído un comunicado, en el cual señalaba que "sobre la tierra criolla, pródiga y rica, hay hambre y miseria", producto del "sistema capitalista, que consagra el imperio del egoísmo, la avaricia y el dinero", para añadir que combatían tanto al marxismo como al liberalismo". ${ }^{24}$

Sin embargo, para julio de 1973, apenas un mes después de la presentación oficial de la ALN, un informe aparecido en Prensa Confidencial el 23 de julio daba cuenta de la primera escisión en la organización. Aparentemente Horacio Calderón y Luis A. Recio (Secretario de Prensa y Propaganda y Jefe de la Alianza Universitaria Nacionalista respectivamente) presentaban sus renuncias indeclinables. Según el periódico, las renuncias de ambos dirigentes apuntaban por elevación a un más amplio objetivo, consistente en canalizar todo el apoyo posible a la Escuela de Conducción Política, bajo la dirección intelectual de Jaime María de Mahieu. Tanto Calderón como Recio contaban con el apoyo de estudiantes secundarios y universitarios cuya incorporación a la Alianza quedaba condicionada a la definición de esa crisis interna. Ese grupo de reserva, que hasta el momento había actuado sigilosamente como "La Legión", pasaría entonces a constituir los estamentos básicos de la "Legión Revolucionaria Peronista", bajo los ideales comunitaristas de Mahieu.

De todas formas ambas organizaciones continuaron su trabajo dentro de la universidad siendo parte de la CEUP. Una entrevista hecha al militante de la Alianza Universitaria Nacionalista "camarada" Zanotti, por el periódico Alianza, puede darnos una idea de la importancia que asignaba la organización a la cuestión universitaria. Ésta integraba la Coordinadora de Estudiantes desde sus comienzos, "siendo una de las agrupaciones gestoras de la definitiva unidad entre los grupos de la ortodoxia Peronista y el Nacionalismo argentino", a su cargo había quedado la Secretaría de Asuntos Estudiantiles. Interrogado Zanotti sobre el panorama de fuerzas de AUN en las diversas Facultades respondía:

-En este momento AUN cuenta con muchos camaradas universitarios en diversas Facultades y se encuentra en pleno periodo de expansión no solamente en la Capital sino también en el interior del país es un ejemplo de ello la Alianza Universitaria de Rosario en la provincia de Santa Fe donde ya nuestros cuadros, a través de informes publicados en el periódico del movimiento, han informado de la caótica situación que alli reina en el ambiente universitario desquiciado por los marxistas y liberales, contra los que AUN ha empeñado una lucha sin cuartel que no se agotará en lo meramente declarativo.

${ }^{24}$ El Día, 22 de mayo de 1973. 


\title{
- ¿Cuál es el pensamiento de Alianza Universitaria Nacionalista sobre el problema Universitario?
}

\begin{abstract}
- Nuestro pensamiento es claro y preciso en la materia y coincide en un todo con la obra que viene llevando a cabo el Camarada Alberto Ottalagano en la Universidad de la sinrazón que nos legaron los marxistas y los liberales, contra los que la AUN ha empeñado una lucha sin cuartel que no se agotará en lo meramente declarativo (...) por ello es que la Misión Ivanissevich en la Universidad no es más que una vuelta a lo que la Universidad nunca deberla haber dejado de ser un lugar donde el conocimiento se encamine a servir a Dios, a la Patria y a la Ciencia. $(. . .)^{25}$
\end{abstract}

Respecto al caso de la Legión Revolucionaria Peronista su dirigente, Horacio Calderón, autor del panfleto antisemita "La Argentina Judía", actuaría vinculado a la intervención de Ottalagano, siendo a partir de septiembre de 1974 asesor en el área de Planeamiento y secretario de Prensa y Difusión de la Facultad de Filosofía y Letras durante el decanato de Sánchez Abelenda entre 1974 y 1975. Pasaría ese mismo año a desempeñarse como Director de Prensa y Difusión de la Universidad de Buenos Aires hasta el golpe de Estado. En diciembre de 1974, tal como lo señalaba el cuadro elaborado por Carta Política, el mismo Calderón daría por disuelta su organización en una carta enviada al semanario El Caudillo. ${ }^{26}$

Respecto al MUN, su presencia ya había sido denunciada por Miguel Talento, presidente de la FULNBA (Federación Universitaria para la Liberación Nacional de Buenos Aires) quien en una nota del diario Noticias del 6 de abril de 1974 había dicho: "La FULNBA les pide a los compañeros que no se dejen arrastrar por las provocaciones, como la que ocurrió en Derecho, donde un grupo de matones bajo la sigla del GAPMUN, intentó romper a tiros una asamblea. La única garantía es permanecer movilizados y en estado de alerta". ${ }^{27}$

A esto el MUN respondió en un reportaje a la revista Consigna Nacional ( $N^{\circ} 9$ abril de 1974) negando su autoría y señalando: "Estamos pues en una labor de orden político cultural claramente definida como una actividad de no agresión como lo solicitara el Recto Solano Lima". A su vez rechazaban la asamblea estudiantil realizada el 4 de abril con presencia de organizaciones de izquierda donde fueron repudiados y expulsados. A lo que señalaban: "El espacio ganado nos ha costado sacrificios, trabajos y voluntad de servicio. Así, pues, permaneceremos en la Universidad sin importarnos un ardite las asambleas que nos expulsen, puesto que si ella es de los trabajadores, sólo estos y Perón podrán decidir sobre la inconveniencia de nuestra presencia”.

\footnotetext{
25 “Alianza Universitaria Nacionalista en la UNBA”, Alianza, Nº10, 29 de noviembre de 1974, p. 3.

26 “Calderón: Disuelve la Legión Revolucionaria Peronista”, El Caudillo, N 55, 20 de septiembre de 1974, p. 6.

27 "Confirman a cuatro decanos en la UNBA", Noticias, No 133, 6 de abril de 1974, p. 11.
} 
Respecto al MUJ la revista Carta Política lo ubica como recién formado en 1974, aunque si prestamos atención al testimonio del abogado y miembro de la CNU Gustavo Demarchi, él había sido uno de los cofundadores de la organización en la Facultad de derecho de la ciudad de La Plata en 1965. En1996, según él mismo señala, el MUJ rechazó la incorporación al FURN (Frente Universitario de la Revolución Nacional) "por representar a los intereses del gobierno militar en la universidad". ${ }^{28}$

Por último, una de las organizaciones de la CEUP con mayor desarrollo en el ambiente universitario era la CNU. El nacimiento de esta organización estaba estrechamente relacionado con las derivaciones de la filial platense del grupo nacionalista Tacuara. Fue justamente a partir de 1964, cuando en virtud de una división, el sector pro peronista de la organización, conformado por Félix Navazo, Martín Sala y Patricio Fernández Rivero comenzó a reunirse con asiduidad en el Instituto Cardenal Cisneros, cuyo principal referente era el profesor y filósofo peronista Carlos Disandro. Señala Carnagui (2013) que las reuniones del Instituto conformaron un nuevo espacio de articulación y sociabilidad en cuyo seno se forjó la Concentración Nacional Universitaria. Los primeros pasos de la CNU se enfocaron en las distintas iniciativas del Instituto Cisneros, fundamentalmente en la organización de conferencias, la publicación de la revista La Hostería Volante y en el acompañamiento a las charlas que realizaba Disandro por el país.

Según Carnagui (2016), fue en uno de estos recorridos que los integrantes de la CNU entraron en contacto con un pequeño grupo de jóvenes nacionalistas de la ciudad de Mar del Plata, escindido de Tacuara en 1967. Producto de estos frecuentes contactos, en agosto de 1971 en el teatro Alberdi de Mar del Plata, fue presentada públicamente la CNU. En el acto de cierre hicieron uso de la palabra Carlos Disandro y el entonces Secretario General de la Confederación General del Trabajo (CGT), José Ignacio Rucci. Si algo caracterizó a la CNU fueron sus acciones directas en el ámbito universitario donde se hizo célebre por romper asambleas y enfrentarse a la izquierda estudiantil. Un ejemplo de esto fue en septiembre de 1968, cuando se conmemoraba el segundo año del asesinato de Santiago Pampillón y la Federación Universitaria Platense había convocado a un paro con movilización para impedir el dictado de clases. En ese momento se presentaron algunos miembros de la CNU y se produjo un enfrentamiento de considerables dimensiones que incluyó el uso de armas de fuego. En diciembre de 1971, la CNU apareció en todos los medios periodísticos cuando integrantes de la organización marplatense asesinaron a Silvia Filler en una asamblea de estudiantes de la Facultad de Arquitectura de la Universidad Provincial de Mar del Plata.

Con respecto al proyecto universitario de la CNU este es posible observarlo en una serie de volantes ${ }^{29}$ que distribuyó la organización en agosto de 1972. El primero reproducía la llamada "Ley Guardo" No 13031 de 1947 que sentaba las bases de la Educación Universitaria. En un claro acto reivindicativo convocaban a retomar la ley

\footnotetext{
${ }^{28}$ Véase su testimonio en el blog personal: http://blogsdelagente.com/gustavodemarchi/tag/actualidad/?doing_wp_cron

${ }^{29}$ CPM-DIPBA, Mesa “Antecedentes”, Legajo 154, folios 15-35.
} 
del peronismo que, entre otras cosas, dejaba el nombramiento de los rectores en manos del Poder Ejecutivo, excluía a los estudiantes del gobierno universitario, señalaba como objetivo de la universidad "afirmar y desarrollar la conciencia nacional" y excluía la actividad política de la vida universitaria. En ese mismo volante la CNU condenaba la Reforma de 1918 que "hábilmente canalizada por Irigoyen" consiguió poner a la Universidad en sintonía con el proceso revolucionario en Rusia: "Se introducen así, los 'soviets' de profesores, estudiantes y graduados que, operando con sentido histórico marxista son la base de las futuras trenzas antinacionales".

También condenaba, sin embargo, "el proceso de destrucción de la Universidad" a partir de la creación de universidades privadas en 1958 puesto que desjerarquizaba a la universidad estatal. En una clara diferenciación con lo que años antes había sostenido Tacuara, la CNU planteaba que fue "una coalición de reformistas y marxistas" (Risieri y Silvio Frondizi, Bernardo Houssay, José Paco, Rolando García y "sedicientes católicos" (Monseñor Octavio Derisi, Atilio Dell Oro Maini, Ricardo Zorraquín Becú) la responsable de la destrucción de la universidad. Para la CNU la acción de los ministros católicos había abandonado a su suerte la universidad pública y convertido las universidades privadas en un negocio vinculado a intereses empresarios. En su visión sostenían que la "universidad libre": "está prácticamente de espaldas a la nación, orientada por una cristiandad jesuítica que busca destruir los últimos restos de nuestra tradición hispánica.". Y que políticamente favorecía un pluralismo que es "la máxima conquista de los poderes internacionales del dinero contra el espíritu y de la tecnocracia bolche contra el sentido de una empresa nacional". Que científicamente eran un desastre porque "no pueden ni podrán reasumir la totalidad de la sabiduría heleno-cristiana" favoreciendo entonces "la dialéctica bolche", y finalmente que económicamente no tenían otra salida que "su vínculo con los sectores oligárquicos del dinero, su dependencia con recursos internacionales y su restricción permanente en lo que atañe a una verdadera empresa cultural". Para la CNU la llegada de Illia continuaba con la destrucción de la Universidad a través del "clan reformista-jesuítico-judío". La asunción de Onganía tampoco modificaba la situación, según la CNU, ya que bajo la falsa imagen del orden y la autoridad, no se derogó el decreto ley de la Revolución Libertadora, ni se modificó la existencia de universidades privadas sostenida por Frondizi, ni se removió la conducción marxista de los claustros profesorales. El volante terminaba con la consigna "Soberanía política-independencia económica-justicia social, ¡Viva la Patria!'”. Entrevistados por la revista Patria Bárbara en septiembre de 1973 volvían a sostener que cualquier intervención en la universidad debía hacerse "en base a la Doctrina Justicialista y la ley 13.031/47 con las modificaciones que sean necesarias pero sin alterar su espíritu". ${ }^{30}$

Es evidente que la CNU heredaba varias concepciones del nacionalismo de derecha ya presentes en Tacuara, pero las resignificaba en el marco de su proceso de peronización en el que Disandro tuvo un papel central. Las múltiples y variadas construcciones del enemigo conformadas por el antiliberalismo, el anticomunismo, el

30 “Reportaje a la Concentración Universitaria Nacional", Patria Bárbara, №25, 17 de septiembre de 1973, p. 11. 
antiimperialismo y el antijudaismo eran una clara expresión del legado nacionalista que se integraba al peronismo. Estas fueron sistematizadas por Disandro bajo la noción de "sinarquía" y aludían a un complot entre poderes mundiales que tenían como fin el debilitamiento de la nacionalidad.

No es de extrañar que varios de estos militantes consustanciados con la política de Ivanissevich y Ottalagano participaran de la gestión e incluso conformaran el cuerpo de celadores ${ }^{31}$. Friedemann advierte también la presencia de militares retirados, e incluso "se creó un "área de situación" dependiente del rectorado con el objetivo de "mantener datos estadísticos para tomar decisiones inmediatas" y se nombró como asesor de la misma a un ex Capitán de Aeronáutica" (2016: 20).

Las medidas represivas continuaron y al ya declarado cierre de los establecimientos hasta el mes de octubre se sumó a partir de ese momento la prohibición de realizar asambleas (estudiantiles, docentes o no docentes) en las facultades. Cuando la FUA y la FULNBA intentaron convocar a un paro en rechazo a estas medidas y a la violencia creciente, Ottalagano respondió con otra resolución donde declaraba que aquellos estudiantes que no pudiesen justificar sus inasistencias serían expulsados de la universidad. Esta medida fue apoyada por la CEUP que en un comunicado aparecido en El Caudillo reclamaban entre varias medidas:

2.- Solicitar a las autoridades universitarias la expulsión inmediata del personal que no se presente a cumplir sus tareas, reemplazándolo automáticamente con la gran cantidad de auténticos trabajadores, deseosos de colaborar en la empresa revolucionaria que preside nuestra compañera ISABEL DE PERON. (.)

4. - Apoyar incondicionalmente al compañero DR. ALBERTO OTTALAGANO, a quien acompañaremos permanentemente en respaldo de las determinaciones nacionales y Justicialistas, que éste asuma y realice.

5. - Ordenar la movilización total de sus cuadros, solicitando el respaldo activo de las organizaciones hermanas justicialistas, a efectos de arbitrar los medios para accionar contra el enemigo, en el terreno y oportunidad que las circunstancias hagan necesario... ${ }^{32}$

${ }^{31}$ Otro de los militantes que participaron de la gestión de Ottalagano, con un cargo en la Facultad de Ingeniería, fue Luis Zarattini, antiguo integrante de Tacuara en la década del sesenta y posteriormente de la ALN. Durante la última dictadura se convirtió en agente civil del Batallón de Inteligencia 601 y fue asignado en Centroamérica como instructor de grupos contrarrevolucionarios. En octubre de 2001 figuró en la lista bonaerense de candidatos a diputados nacionales del Partido Popular de la Reconstrucción, vinculado a Mohamed Alí Seineldín. (Cersosimo, 2015: 295).

32 “Coordinadoras de estudiantes repudian la provocación”, El Caudillo, № 50, 8 de noviembre de 1974, p. 13 
La ideología nacionalista, católica y fuertemente anticomunista de Ottalagano se plasmó en varias medidas adicionales. Dio directivas para que en los programas de Historia y Geografía de los colegios dependientes de la universidad se destaquen especialmente las acciones bélicas de las Fuerzas Armadas, al mismo tiempo que solicitó al Ministerio de Defensa que designase a tres historiadores y geógrafos militares a fin de proceder a formar a los rectores de los institutos. ${ }^{33}$. Procedió también a la creación de un Instituto de Defensa Nacional y Seguridad de posgrado en coordinación con el Ministerio de Defensa.

Para fines de noviembre de 1974 El Caudillo destacaba las medidas y posicionamientos de Abalenda y Ottalagano:

El presbítero Raúl Sánchez Abelenda encomendó la protección de María, Madre de la Iglesia para su gestión como flamante decano de la Facultad de Filosofía y Letras. Era toda una definición, cargada de significados. A pocos pasos de él, con los puños apoyados sobre un escritorio, Alberto Ottalagano había dicho unas palabras que se complementaban perfectamente con las anteriores. Sentó una premisa: "O con Cristo o contra Cristo". Para después agregar que la suprema alternativa es en el país la de justicialismo o marxismo, y que a esa opción deberían adecuarse dentro de no mucho tiempo todos los miembros de la partidocracia supérstite. ${ }^{34}$

A las cesantías masivas se sumaban las amenazas y atentados contra docentes y estudiantes, muchos de los cuales optaron por exiliarse, como fueron los casos de Jorge Taiana, Alfredo Ibarlucía, Raúl Laguzzi, Rodolfo y Adriana Puiggrós. Durante el mes de noviembre fueron detenidos los dirigentes estudiantiles Miguel Talento (presidente de FULNBA) y José Pablo Ventura (JUP) y el 29 de noviembre, el secretario gremial del Centro de Estudiantes de Ingeniería y militante maoísta del FAUDI ${ }^{35}$, Daniel Winer, fue secuestrado dentro de la facultad presuntamente por un grupo de celadores, cuando había concurrido a rendir un examen. Su cadáver baleado apareció en un descampado y un desconocido "comando Mazorca" se atribuyó el hecho. En una entrevista de hace algunos años ${ }^{36}$, el dirigente estudiantil Miguel Ponce, fundador de la agrupación Juventud Radical Universitaria, relató que el ex decano de Ingeniería Jorge Roulet le había comnetado que un no docente lo llamó a su casa para denunciar que quienes habían secuestrado a Winner eran los cuatro integrantes del Comando Mazorca de la Triple A de apellido Soaje Pinto, Peralta Tanco, Boccardo y Recio. El joven militante

\footnotetext{
33 "Dispuso Ottalagano que en los estudios históricos se destaquen las acciones de las Fuerzas Armadas", La Opinión, 11 de diciembre de 1974.

34 "Justicia: Dar a cada uno lo suyo", El Caudillo, №52, 26 de noviembre de 1974, p. 4.

${ }^{35}$ El FAUDI (Federación de Agrupaciones Universitarias de Izquierda) se constituyó en 1968 y era el brazo universitario de Partido Comunista Revolucionario.

36 “Soaje Pinto, de la Triple A a Papel Prensa", Veintitrés, Nº751, 22 de noviembre de 2012, p. 27.
} 
radical Ponce llevó esta discusión al seno de su partido (UCR), y el Comité Nacional del radicalismo decidió hacer una conferencia de prensa para denunciar a los cuatro presuntos asesinos del militante universitario de Ingeniería Daniel Winner. Frente a este hecho El Caudillo sostuvo:

En los primeros días de la pasada semana desde el comité central de la UCR se lanzaron dos graves acusaciones contra la Gestión Ottalagano. La primera de ellas fue la denuncia de la desaparición de un estudiante de la Facultad de Ingeniería Dante Winer que posteriormente fue encontrado asesinado. Luego se imputó a personal de la Universidad como autores de torturas y malos tratos contra una alumna del Nacional Buenos Aires. (...)

Dentro de este contexto enmarañado de las rivalidades entre las sectas marxistas puede encajarse el asesinato de Daniel Winer. Winer pertenecía a FAUDI y era uno de los principales mentores de una estrategia tendiente a radicalizar la oposición contra la conducción universitaria. Las circunstancias que rodearon al crimen son típicas de un ajuste de cuentas entre delincuentes comunes. El comunicado de cierta organización presuntamente nacionalista — hasta ahora desconocidaque apareció adjudicándose el hecho, no hace más que echar sombras sobre las motivaciones del episodio y avala la creencia de que en realidad lo que se pretende es desviar el curso de la investigación hacia cauces indefinidos. ${ }^{37}$

Sin embargo, las cuatro personas mencionadas como integrantes del comando Mazorca y responsables del asesinato, no eran figuras desconocidas. Si bien la denuncia no incluye los nombres de los cuatro integrantes, es probable que se refieran a: José María Soaje Pinto, recordado como estudiante de la carrera de abogacía y militante de la ultraderecha ${ }^{38}$, Álvaro Peralta Tanco quien figura como miembro de la Legión Revolucionaria Peronista en la solicitada del 28 de septiembre de 1973 en La Razón, reproducida anteriormente, José María Boccardo ubicado como integrante de la Triple A y como uno de los responsables del asesinato de un nacionalista vasco en 1978 mientras formaba parte de una internacional fascista en España ${ }^{39}$, y por último Luis Alejandro Recio señalado anteriormente como integrante de la Alianza Universitaria Nacionalista y luego de la Legión Revolucionaria junto con Calderón. No hay datos de que la justicia haya avanzado en sus investigaciones sobre estos personajes pero de

\footnotetext{
37 "Universidad, el caos se refugió en la zona zurda". El Caudillo, No 54, 10 de diciembre de 1974, p. 19.

38 "José María Soaje Pinto, el abogado del diablo", Infojus, 15 de febrero de 2014. Disponible en: http://www.infojusnoticias.gov.ar/nacionales/jose-maria-soaje-pinto-el-abogado-del-diablo-3201.html

${ }^{39}$ Yo maté al asesino de Carrero Blanco" El Mundo, No 427, 21 de diciembre de 2003. Disponible en: http://www.elmundo.es/cronica/2003/427/1072098707.html
} 
ser ciertas las acusaciones demostraría el estrecho vínculo entre varios miembros de la derecha peronista y de la Triple A.

Lo cierto es que para diciembre de 1974, cuando la intervención de Ottalagano llegaba a su fin, la misma derecha peronista se congratulaba del éxito de su misión y del desconcierto de la izquierda:

... Cuando los marxistas tomaron como botín de guerra a la Universidad su soberbia por el triunfo obtenido terminó en una grosera anarquía. Por eso sólo Balbín lloró su partida. Ahora que están en precipitada fuga, las peleas intestinas caracterizan las relaciones entre las diversas minifacciones. Es que están buscando un chivo expiatorio de sus desmanes, de su fabulosa ignorancia política. Tras los dos fracasos que significaron las fallidas movilizaciones y huelga general que recientemente habían dispuesto, se intentó con el mismo resultado la instrumentación de un plebiscito. (...) El panorama se complica porque además las sectas de izquierda no logran ponerse de acuerdo sobre una estrategia común contra lo que denominan "política fascista peronista" de Ottalagano. Mientras la FULNBA propicia un enfrentamiento abierto contra las autoridades con movilizaciones y otras acciones subversivas, la FUA participa del criterio de agrupar fuerzas, realizar el congreso unifícador y mantener diálogos con los partidos políticos de oposición. (...) Por último la FULNBA ha postergado para mediados de diciembre la realización de las elecciones, mientras que la fecha del soñado congreso unificador se ha levantado indefinidamente. ${ }^{40}$

Concluía el artículo señalando que "La gran mayoría de los estudiantes han decidido cumplir su función específica que es estudiar y miran con indiferencia esta pelea entre las aves de rapiña. Están decididos a recuperar el tiempo perdido en una Universidad donde ahora si está garantizada la Paz y el Orden". ${ }^{4}$

Finalmente, al terminarse la intervención de Ottalagano, un decreto del Poder Ejecutivo el 26 de diciembre prorrogaba la intervención de la UBA por un año más, hasta el 31 de diciembre de 1975, y nombraba como nuevo interventor al Director Nacional de Relaciones Universitarias del Ministerio de Cultura y Educación, a cargo de la Subsecretaría de Asuntos Universitarios, Julio H. Lyonnet ${ }^{42}$. El decreto concluía agradeciendo "al doctor Alberto Eduardo Ottalagano, cuyo término de designación ha vencido, los importantes servicios prestados". Respecto a los motivos por los cuales Ottalagano no continuó como interventor, señala (Rodríguez, 2015, p. 53) algunos

\footnotetext{
40 "Universidad, el caos se refugió en la zona zurda". El Caudillo, No 54, 10 de diciembre de 1974, p. 19.

41 "Universidad, el caos se refugió en la zona zurda". El Caudillo, No 54, 10 de diciembre de 1974, p. 19.

${ }^{42}$ Decreto $N^{\circ} 2.013$ del 26 de diciembre de 1974. Publicado en el Boletín Oficial el 15 de enero de 1975.
} 
enfrentamientos con el Secretario de Educación Carlos Frattini. Es posible también que los cuestionamientos hechos por la UCR a través de Ricardo Balbín a la presidente María Estela Martínez de Perón, mostrando su disconformidad, hayan contribuido a descartar la idea de prorrogar su designación ${ }^{43}$. De todas formas, fue reemplazado por Lyonett que continuó con la misma orientación ${ }^{44}$.

\section{A modo de conclusión}

A lo largo de este artículo hemos visto como el proceso de depuración al interior del movimiento peronista y de las diferentes esferas de la administración pública cobró especial impulso a partir del Documento reservado de octubre de 1973. En este proceso las organizaciones de la derecha peronista como la Juventud Sindical Peronista, la Juventud Peronista de la República Argentina, el Comando de Organización, la Alianza Libertadora Nacionalista y la Concentración Nacional Universitaria junto a publicaciones como El Caudillo, Alianza, Patria Peronista y Las Bases, entre otras, apoyaron el afán depurador y anticomunista de los funcionarios peronistas. Este proceso de desplazamiento de los sectores de izquierda del peronismo se llevó a cabo recurriendo a medios tanto legales (Ley de Prescindibilidad, Ley de Asociaciones Profesionales, modificaciones al Código Penal) como ilegales (donde organizaciones como la CNU y sectores de la UOM sumaron su accionar a la violencia paraestatal de la Triple A conducida por López Rega y la Policía Federal y al accionar represivo del mismo Estado). De este afán depurador no quedaron exentas las universidades nacionales, las cuales ya desde la misma asunción de Perón fueron objeto de diversas medidas tendientes al desplazamiento de funcionarios y docentes (como Puiggrós, Ortega Peña, Duhalde, entre otros tantos). Esta situación se intensificó particularmente con el inicio de la llamada por la prensa "misión Ivanissevich" y en el caso de la UBA con el rectorado de Ottalagano. A las diversas modificaciones y medidas represivas durante esta gestión se sumó el accionar de agrupaciones del peronismo de derecha nucleadas en la Coordinadora de Estudiantes Universitarios Peronistas como la Concentración Nacional Universitaria, el Movimiento Universitario Justicialista, el Movimiento Universitario Nacional, la Alianza Universitaria Nacionalista y la Legión Revolucionaria Peronista. Tenían en común el origen en el nacionalismo de derecha y una interpretación del peronismo en la cual reivindicaban el carácter anticomunista, católico, hispanista e incluso antisemita del peronismo. Su accionar, si bien minoritario en términos numéricos, comparado con el resto del movimiento estudiantil, fue decisivo al aportar funcionarios a la gestión de Ottalagano e incluso personal a su grupo de celadores, los cuales llegaron a ejercer la represión violenta sobre estudiantes y docentes a través de amenazas y asesinatos.

En este sentido, coincidimos con Friedemann (2016) cuando sostiene que el carácter represivo que impregnó a la Universidad de Buenos Aires desde septiembre de 1974 habilita a sostener la idea de una "transición a la dictadura", en tanto allanó el

\footnotetext{
${ }^{43}$ Véanse las declaraciones de Ottalagano a la prensa negando presiones de la UCR y sosteniendo "recibí la universidad del caos y dejé la universidad del orden" en El Día, 28 de diciembre de 1974.

${ }^{44}$ Respecto a la gestión del interventor Lyonet véase Seia, 2016: 36-38.
} 
camino a la sistematización de la represión ilegal. Por supuesto, con esto no queremos decir que el accionar de la dictadura estuviera prefijado con antelación pero sí que la represión ejercida a partir de 1976 lo hizo sobre un ámbito universitario que ya había sido diezmado. Esto tampoco debe hacernos olvidar, como señalan Califa \& Millán (2016) la existencia de elementos represivos previos a la misión Ivanissevich, la cual si bien significó un cambio cualitativo con respecto al pasado, lo fue "no tanto por presentar elementos "nuevos", sino por combinar y aumentar sensiblemente el uso de tácticas represivas ya existentes".

\section{Referencias bibliográficas}

Abbatista, M. L. y Carnagui, J. L. 2014. "La “depuración oficial” en las políticas educativas: la gestión Ivanissevich en el Ministerio de Educación de la Nación y su impacto en la UNLP”. VIII Jornadas de Sociología de la UNLP. La Plata.

Antúnez, D. H. 2015. Caras extrañas. La Tendencia Revolucionaria del Peronismo en los gobiernos provinciales (Buenos aires, Córdoba, Mendoza, Santa Cruz y Salta 1973-1974. Buenos Aires: Prohistoria.

Baschetti, R. (Ed.). 1999. Documentos 1973-1976. Volumen II. De la ruptura al golpe. La Plata: de la Campana.

Besoky, J. L. 2014. O nacionalismo populista de direita na Argentina: a aliança libertadora nacionalista, 1937-1975. Mediações - Revista de Ciências Sociais, 19 (1), 61. http://doi.org/10.5433/2176-6665.2014v19n1p61

Buchbinder, P. 2014. "La Universidad y el tercer peronismo: notas sobre el debate parlamentario en torno a la Ley Taiana”. En: M. Millán (Ed.), Universidad, política y movimiento estudiantil en Argentina (entre la "Revolución Libertadora. y la democracia del '83). Buenos Aires: Final Abierto.

Califa, J. y Millán, M. 2016. "La represión a las universidades y al movimiento estudiantil argentino entre los golpes de Estado de 1966 y 1976". En: Revista de Historia Iberoamericana, 9(2), 10-38.

Carnagui, J. L. 2013. “El nacionalismo juvenil platense y la formación de la Concentración Nacional Universitaria (CNU), 1960-1971”. En: Nuevo mundo mundos nuevos.

Carnagui, J. L. 2016. Nacionalistas, católicos y peronistas. Auge, afianzamiento y reconfiguración de la Concentración Nacional Universitaria (CNU) La Plata, 1955-1974. Universidad Nacional de La Plata.

Cersósimo, F. 2015. «El Proceso fue liberal». Los tradicionalistas católicos argentinos y el Proceso de Reorganización Nacional (1976-1983). Universidad de Buenos Aires.

Friedemann, S. 2016. "Transición a la dictadura durante el gobierno de Isabel Perón . E1 ocaso de la Universidad Nacional y Popular de Buenos Aires". En: Entramados y Perspectivas, 6(6), 1-34.

Larraquy, M. 2007. López Rega: El peronismo y la Triple A. Buenos Aires: Punto de Lectura. Millán, M. 2015. Conflicto universitario y estudiantil en la UBA durante el rectorado de Rodolfo Puiggrós (junio - octubre de 1973). En: Conflicto Social, 8(14), 64-92. 
Millán, M. 2016. La Juventud Universitaria Peronista en las memorias de la militancia estudiantil reformista y marxista de la. En: Historia, Voces y Memoria, 5369 (10), 49-64.

Rodriguez, L. G. 2014. La universidad durante el tercer gobierno peronista (1973-1976). En: Conflicto Social, 7 (12), 114-145.

Rodríguez, L. G. 2015. Universidad, peronismo y dictadura 1973-1983. Buenos Aires: Prometeo.

Seia, G. 2016. La Universidad de Buenos Aires UBA entre la misión «Ivanissevich» y la última dictadura (1974 1983). Represión, reordenamiento y reconfiguración de la vida estudiantil. Universidad Nacional de General Sarmiento.

Servetto, A. 2010. 73/76: El gobierno peronista contra las "provincias montoneras". Buenos Aires: Siglo XXI.

Svampa, M. 2007. "El populismo imposible y sus actores, 1973-1976". En: D. James, Nueva Historia Argentina. Violencia, proscripción y autoritarismo (1955-1976). Buenos Aires. Sudamericana. Vol. 9, pp. 383-486. 